$\underline{\text { Editorial }}$

\title{
Measles immunisation in Sri Lanka: Sanity prevails, at long last, but better late than never
}

Sri Lanka Journal of Child Health, 2015; 44(2): 73-74

(Key words: Measles immunisation, Sri Lanka)

It is now close to four years since the Expanded Programme of Immunisation (EPI) was revised by the Ministry of Health of Sri Lanka. One change that was instituted was the shifting of the timing of the measles immunisation. The measles vaccine was previously given at the age of nine months. At the revision, the powers that be decided to convert it to the Measles Mumps Rubella (MMR) vaccine, to be given at twelve months rather than at nine months. The live Japanese Encephalitis Vaccine, which was earlier given at 9 months, was shifted to be given at 12 months.

In an Editorial in the Sri Lanka Journal of Child Health in June $2012^{1}$, this writer expressed some grave concerns regarding the timing of the MMR vaccine, particularly with respect to protection of infants, especially in the second half of infancy ${ }^{1}$. A comprehensive review of the status of maternal and infantile measles antibody status was presented and following the revision of the EPI schedule the possibility of a resurgence of measles in the second half of infancy in Sri Lanka was postulated. In fact the Editorial concluded with the following narrative. "Even with all the incredible results that have been secured so far in our EPI Programme, one cannot be complacent and be reassured that all will be well in the future. We need to be vigilant to the unfolding information from all over the globe and take steps to reassess the situation regarding any modifications to a system with a splendid track record. The concerns aired in this editorial are made in good faith, in a concerted effort just to make such a winning regime, that much better"1.

The same writer, in December 2011, in a Letter to the Editor in the Ceylon Medical Journal wrote " $B y$ not giving the measles vaccine at nine months and giving the MMR at one year, one may be leaving a group of infants in the second six months of infancy quite vulnerable to measles and at risk of major complications. I am inclined to think that there is a remote possibility that this may cause some problems in the future. I have written to the powers that be, regarding this possibility some time ago, but it has fallen on deaf ears. However, I desperately hope that I am wrong, for the sake of the future children of our country "2.
The rest is history. Those prophetic statements unfortunately came true. There was indeed an unprecedented resurgence of measles in infancy over the last couple of years in this country. The majority of these cases were in the 9 to 12 month age group. The situation caused so much concern due to the morbidity and even some mortality in these affected infants, the Ministry of Health was compelled to administer the live attenuated measles vaccine at nine months of age to a cohort of infants to try and mitigate the situation. It was a desperate measure to try and contain a very real threat. However, the paediatricians are still seeing some cases in the country, albeit not in the same numbers that occurred previously.

The intricacies of the debacle of the resurgence of measles were discussed at length at the Sri Lankan National Vaccine Summit held in the early part of this year. The representatives from the Sri Lanka College of Paediatricians made a compelling case for a re-examination of the timing of the MMR vaccine. There was general agreement that MMR vaccine needed to be given earlier.

Now, in an Administrative Circular ${ }^{3}$, the Director General of Health Services of the Sri Lankan Ministry of Health has taken steps to revise the EPI schedule from $1^{\text {st }}$ April 2015. The new schedule will provide MMR vaccination at nine months and administer the Live Japanese Encephalitis vaccine at twelve months. In all fairness, the Ministry of Health has taken up the advice offered by the Sri Lanka College of Paediatricians. Though it has taken quite some time, sanity has prevailed, at long last, and most certainly, better late than never. Even after the latest revision, if new cases continue to occur, our considered opinion is that one might even have to seriously consider administering an extra dose of attenuated live measles vaccine to all infants at six months of age.

There are perhaps some lessons to be learned from such a fiasco. It is imperative that the policy makers are firmly advised to be extremely careful in changing a "winning team". Our EPI was indeed such a winning venture, perhaps a model for many other countries, especially in the region. Our considered opinion is that all aspects have to be considered and adequate discussion amongst all 
concerned must be undertaken before such a change to an excellent programme venture is undertaken.

It must be reiterated, even if it has not been that well appreciated before, that the personnel of the Sri Lanka College of Paediatricians have the experience and expertise to provide advice on any and every child health issue that can crop up in the country. One should appreciate that their considered opinion being obtained should be a sine qua non prior to even considering any and every change, however small, to the protocols of looking after the child health care of the country. In that context, we can only echo the sentiments embodied in the documented and much admired vision of the College, "to promote a profession and a nation that cherishes the perpetual value of children and envisage the attainment of the golden goal of providing the finest of healthcare services to all children of this resplendent isle".

\section{References}

1. Perera BJC. Editorial. Some thoughts on the revised Sri Lankan expanded programme of immunisation. Sri Lanka Journal of Child Health 2012; 41(2): 53-5. http://dx.doi.org/10.4038/sljch.v41i2.4390

2. Perera BJC. Letter to the Editor. Measles, mumps, rubella (MMR) vaccine - a reply (1). Ceylon Medical Journal 2011; 56:185. http://dx.doi.org/10.4038/cmj.v56i4.3908 PMid:22298221

3. Mahipala PG. Change of the National Immunization schedule: MMR, LJE vaccination. Circular from The Ministry of Health and Indigenous Medicine of Sri Lanka dated 18/03/2015 of reference My No. EPI/14/2015

\section{B J C Perera}

Joint Editor 